\title{
Reduction of grazing activity of two estuarine copepods in response to the exudate of a visual predator
}

\author{
Matthew D. Cieri*, Donald E. Stearns ${ }^{* *}$ \\ Department of Biology, Rutgers University, Camden, New Jersey 08102, USA
}

\begin{abstract}
A grazing zooplankter may minimize its susceptibility to visual predation by reducing its gut contents or its feeding movements. Such behavioral mechanisms require (1) that the prey can detect the predator and (2) that it reduces its grazing activity when light conditions favor visual predation. In this work we have examined the grazing activity of 2 estuarine copepods, Acartia tonsa and Acartia hudsonica, in the chemical presence or absence of its natural visual predator, the Atlantic silverside Menidia menidia. Our results indicate that in the presence of chemical exudates of $M$. menidia, A. tonsa and A. hudsonica reduced their gut fullness. This response was observed only when light levels were high enough for visual predation. Reduction in gut fullness resulted from decreased ingestion rates, not from changes in gut evacuation rates. Light intensity was found to affect the grazing response to the fish-exuded chemical(s). Such behavior may be advantageous to these copepods in estuaries which contain large numbers of visual predators.
\end{abstract}

KEY WORDS: Acartia tonsa - Acartia hudsonica - Menidia menidia - Visual predation - Nocturnal feeding $\cdot$ Copepod grazing $\cdot$ Copepod behavior $\cdot$ Fish exudates

\section{INTRODUCTION}

Day-night differences in grazing activity of zooplankton have been well documented in marine and freshwater environments (reviewed by Haney 1988). In situ, many zooplankton species have lower gut fullness levels during daylight hours than at night. Lower levels of gut fullness during daylight hours may be adaptive in reducing visibility to predators (Stearns 1986, Arfi et al. 1992, Bollens \& Stearns 1992). Reduction of visual predation risk may be accomplished by minimizing daytime feeding movements that might otherwise increase the probability of visual detection (Zaret 1972, Kislalioglu \& Gibson 1976) or by reducing gut pigmentation levels that might increase visibility of

Present addresses:

- School of Marine Sciences, University of Maine, Orono, Maine 04469, USA.E-mail: matthew_cieri@umit.marine.edu

- Department of Biological Sciences, Wagner College, Staten

Island, New York 10301, USA an otherwise largely transparent organism ( $\mathrm{O}^{\prime}$ Brien 1979, Giguère \& Northcote 1987).

While nocturnal grazing may be adaptive in minimizing exposure to visual predators, zooplankton that feed continuously may consume more phytoplankton over a $24 \mathrm{~h}$ period (but see McAllister 1971) and thus increase daily egg production compared with nocturnal feeders, especially when considering zooplankton species that do not rely heavily on stored food reserves (e.g. Acartia tonsa [see Dagg 1977]). In 2 field experiments in different USA East Coast estuaries, Stearns et al. (1989) found that egg production of A. tonsa correlated well with gut fullness measured 24 to $27 \mathrm{~h}$ earlier. Given this possible disadvantage of nocturnal feeding, it would seem most adaptive for a zooplankter to have a mechanism for switching from continuous feeding in the absence of visual predators or lighting conditions conductive to visual predation to nocturnal feeding in the presence of visual predators when lighting conditions would otherwise allow visual predation to occur. 
The purpose of this research was to examine the effect of chemicals exuded by fish on the grazing activity of Acartia tonsa and Acartia hudsonica and to determine the effects of light intensity on this behavior. In a series of laboratory experiments, the grazing activities of these estuarine copepods were examined in the presence and absence of exudates from a natural visual predator, the Atlantic silverside Menidia menidia. Three experimental approaches were used: (1) feeding experiments conducted under constant light conditions to examine the effect of fish exudates on copepod gut fullness, (2) gut evacuation experiments to examine the effect of fish exudates on gut fullness during gut evacuation, and (3) a feeding and light intensity experiment to examine the effect of light intensity on copepod gut fullness in the presence and absence of fish exudates.

\section{MATERIALS AND METHODS}

Collection and maintenance of test organisms. Menidia menidia were collected in Great Bay near Rutgers University Marine Field Station, Tuckerton, New Jersey, USA, from July 1994 to April 1995, using a $6.1 \mathrm{~m}$ bag-seine. The fish were transported directly to laboratory facilities (Rutgers University, Camden, New Jersey, USA), in plastic buckets and were equilibrated overnight to room temperature $\left(23\right.$ to $\left.25^{\circ} \mathrm{C}\right)$. These fish were then placed in $114 \mathrm{l}$ holding tanks containing 30 psu artificial seawater (Cieri 1996, Nemetz 1996). Fish were then observed for approximately 2 to $4 \mathrm{~d}$ to determine overall health. If an individual fish was either not feeding or displayed non-normal swimming behavior after the observation period, it was removed from the holding tank and euthanized.

Zooplankton were collected from the same area using a tidally flushed, $335 \mu \mathrm{m}$ mesh plankton net. Acartia tonsa were present during the fall and early winter. Acartia hudsonica dominated collections made during the winter and spring The zooplankton were transported to the laboratory, then allowed to equilibrate overnight in aerated buckets to room temperature $\left(21\right.$ to $\left.23^{\circ} \mathrm{C}\right)$. Approximately 20 to 30 undamaged adult females of either species were then sorted under a dissecting microscope. The females were then transferred into $30 \mathrm{ml}$ Nalgene ${ }^{\otimes}$ beakers containing glassfiber filtered artificial seawater ( $30 \mathrm{psu}, \mathrm{FASW}$ ). The copepods were fed with a culture of Thalassiosira weissflogii. The beakers were placed in an illuminated incubator with constant fluorescent light $\left(16.8 \mu \mathrm{E} \mathrm{m} \mathrm{m}^{-2}\right.$ $\mathrm{s}^{-1}, 400$ to $700 \mathrm{~nm}$ range, beaker level) and temperature $\left(23^{\circ} \mathrm{C}\right)$. The constant light environment of the incubator was chosen to depress the diel rhythm often associated with $A$. tonsa feeding behavior (Stearns
1986). Copepods were left in this environment for at least $72 \mathrm{~h}$ prior to experimentation, being disturbed only when the diatoms were gently resuspended (via wide bore pipette) once every day. Problems associated with excess handling found by Arashkevich (1975) for A. tonsa were thus reduced. Mortality during this period was approximately $10 \%$. Log phase growth cultures of the diatom T. weissflogii (Clone VA59) were used throughout as the food item for all experimentation and maintenance of copepods.

Preparation of the exudates from Menidia menidia. Six healthy Menidia menidia were isolated from the holding tanks and placed in aerated and covered, $4 \mathrm{l}$ glass jars that contained FASW. Individual $M$. menidia were always between 6 and $8 \mathrm{~cm}$ in total length. No water in which dead fish were found was ever used for experimental purposes. The fish were held in the jars without food, for $72 \mathrm{~h}$. Following incubation, the fish were removed and the water filtered through a $47 \mathrm{~mm}$ glass-fiber filter. This water (hereafter termed fish exudate) was poured into a clean $500 \mathrm{ml}$ bottle and allowed to equilibrate to the same temperature as was used in the experiments.

Effect of fish exudate on feeding activity under constant light conditions. In these experiments we investigated the effects of the fish exudate on the gut fullness of Acartia tonsa at various times after they had begun to feed. Beakers containing copepods were removed from the incubator and randomly assigned to either the 'plus fish exudate' or the 'minus fish exudate' treatment group. These groups were subdivided into various feeding periods $(30,45,60,75$, and $90 \mathrm{~min})$. There were at least 4 beakers for each feeding period per treatment. Each beaker, containing 20 to 30 copepods, was considered a random independent replicate for its exposure group and its experimental feeding period. Acartia hudsonica was similarly tested using 60, 75 and 90 min feeding periods.

The copepods in each beaker were then rinsed with FASW 3 times to remove food items. Rinsing involved the addition of FASW and subsequent removal of water using a wide bore pipette covered with $333 \mu \mathrm{m}$ mesh. After checking the copepods for damage under a dissection microscope, each beaker had its water level adjusted to $5 \mathrm{ml}$. Depending on a beaker's exposure group, $20 \mathrm{ml}$ of either fish exudate or FASW was added. The beakers were then returned to the incubator for 90 min to allow the copepods to empty their guts (Stearns et al. 1987).

Approximately $5 \mathrm{ml}$ of food of known concentration was then added. Volume of food added was calculated such that the final concentration of diatom food was $1.5 \times 10^{4}$ to $2.2 \times 10^{4}$ cells $\mathrm{ml}^{-1}$ in each of the beakers. This addition was made without altering the experimental light or temperature conditions. 
After the appropriate feeding period, the contents of each beaker were passed through a $47 \mathrm{~mm}$ glass-fiber filter (Millipore $\left.{ }^{(}\right)$. These filters, containing both copepods and uneaten food, were immediately placed in plastic petri dishes and frozen $\left(-20^{\circ} \mathrm{C}\right)$ for later gut content analysis.

Effect of fish exudate on gut evacuation under constant light conditions. In this experiment we examined the effect of the fish exudate on the gut evacuation rate of Acartia tonsa. Each beaker was rinsed, prepared with fish exudate or FASW, and the copepods were allowed to evacuate their guts for $90 \mathrm{~min}$. The copepods were then allowed to feed for $90 \mathrm{~min}$ at the same food concentrations described earlier. After feeding, replicates assigned to gut evacuation period 0 min were filtered and immediately frozen for later gut content analysis. Replicate beakers assigned to the other 2 gut evacuation periods $(15,30 \mathrm{~min})$ had all food items removed by rinsing with FASW, as described above, and were allowed to stand for the appropriate period, before being filtered and frozen for later gut content analysis.

Effect of light intensity and fish exudate on copepod feeding activity. In this experiment we examined the effect of the fish exudate and light intensity on the gut fullness of Acartia tonsa. Each beaker was rinsed and prepared with or without fish exudate as described earlier. Replicates were further divided into groups such that 5 replicates were exposed to 1 each of 9 light intensities $\left(0.0,1.0 \times 10^{-3}, 1.0 \times 10^{-2}, 5.0 \times 10^{-2}, 1.0 \times\right.$ $10^{-1}, 1.0,5.28,9.82$, and $26.0 \mu \mathrm{E} \mathrm{m} \mathrm{m}^{-2} \mathrm{~s}^{-1}$ ). Copepods were allowed to empty their guts for $90 \mathrm{~min}$ in an incubator in which they could also acclimate to the appropriate experimental light intensity.

The experimental incubator (Fig. 1) was designed to present an underwater angular light distribution such as would be found near the surface of a turbid estuary with the sun near its zenith (Timofeeva 1974, Stearns 1983). The incubator was set up in a light-sealed room. Beakers were placed on a plexiglass stand positioned in the center of a much larger water bath $(50 \times 50 \times$ $50 \mathrm{~cm}$ ) that had been internally painted flat black to minimize reflection. The water bath was designed such that its walls were outside the critical angle (zenith $\pm 48.6^{\circ}$ ) as viewed from any location within any of the beakers. The water surface of the beakers and water bath was continuous. A Kodak Carousel 4200 slide projector fitted with a FHS, $300 \mathrm{~W}, 82 \mathrm{~V}$ tungsten lamp, which has been shown by Stearns et al. (1994) to have similar spectral transmission properties as sunlight at $1 \mathrm{~m}$ depth, was used as the light source. A Sola CVS constant voltage transformer reduced quantal output fluctuations. Neutral density filters were used to select the appropriate light intensities. The light beam, after emission, was reflected downward by a large mirror. It then passed through a translucent acetate dif-

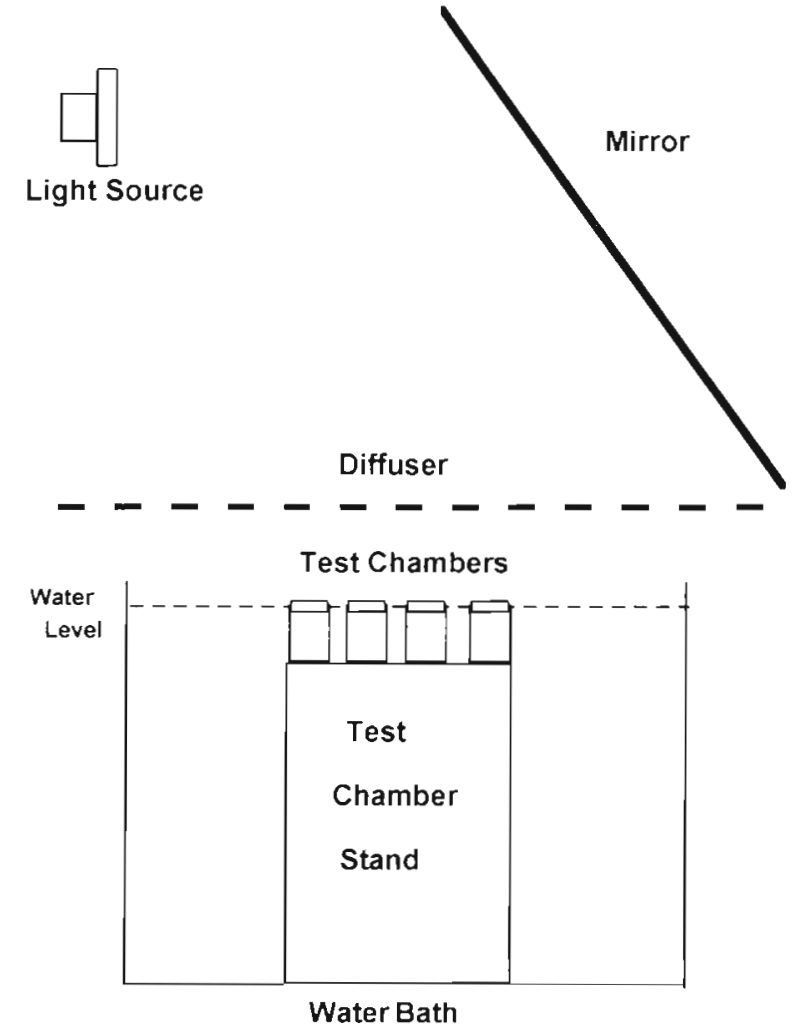

Fig. 1. Diagram of the experimental incubator used for studying the effect of light intensity on feeding of Acartia tonsa in the presence and absence of fish exudates

fuser suspended $10 \mathrm{~cm}$ above the top of the water bath. Surface light intensities within the test chamber region differed by no more than $5 \%$.

After the beakers had been placed in the incubator, diatom culture was added at the same concentration as has been described in the feeding experiments. After a $1 \mathrm{~h}$ feeding period, the copepods were filtered and frozen for later gut content analysis.

Gut content analysis. The general method of gut content analysis can be found in Stearns (1986) and Cieri (1996). Frozen glass-fiber filters, containing 20 to 30 copepods, were thawed at room temperature for about $20 \mathrm{~min}$. Copepods were then removed, individually rinsed 3 times in FASW, and then placed on a clean glass-fiber filter. The copepods were then examined under a dissection microscope to ensure that uneaten food was not adhering to any external surfaces. This second set of glass-fiber filters was ground with cold $\left(1^{\circ} \mathrm{C}\right) 90 \%$ ACS-certified aqueous acetone. A fluorometric method was used for determination of the average gut fullness for each beaker (Yentsch \& Menzel 1963, Strickland \& Parsons 1972). Resulting total pigment (chlorophyll a + pheopigment a) per copepod was normalized for copepod body size by dividing by cephalothorax length (mm). This measurement (ng of 
total pigment copepod $\mathrm{d}^{-1} \mathrm{~mm}^{-1}$ ) is reported as the gut fullness index (GFI). Average cephalothorax length for each sample was determined from measurements on 20 randomly selected individuals collected concurrently with test zooplankton before each experimental run.

Statistical procedure. The GFI values for the replicates were averaged for each treatment group; a standard error was calculated for each mean. Before any parametric tests were done, the data set was tested for homoscedasticity using the $F_{\max }$ test (Sokal \& Rohlf 1987). Parametric tests included the Model I, 3-way analysis of variance (ANOVA), the Model I, 2-way ANOVA, the Model I, 1-way ANOVA, and the Student-Newman-Keuls (SNK) a posteriori simultaneous testing procedure (Sokal \& Rohlf 1969, 1987). Nonsignificance for all tests was determined at $p>0.05$.

\section{RESULTS AND DISCUSSION}

Copepods which exhibit nocturnal feeding behavior show higher levels of gut fullness at night than during day. This behavior reduces the risk of capture by visual predators (Stearns 1986, Haney 1988, Bollens \& Stearns 1992). This behavior, like nocturnal vertical migration (Dodson 1988, Ringelberg 1991, Loose 1993, Loose et al. 1993), is hypothesized to be a behavioral response to a fish-mediated cue (Bollens \& Stearns 1992).

The results of the feeding experiments under constant light and temperature conditions indicated that both Acartia tonsa (Model I, 2-way ANOVA: $F_{\mathrm{s}}=6.45$; $\mathrm{df}=1.39 ; \mathrm{p}<0.01$ ) and $A$. hudsonica (Model I, 2-way ANOVA: $F_{\mathrm{s}}=32.82 ; \mathrm{df}=1,24 ; \mathrm{p}<0.01$ ) had significantly lower levels of gut fullness when exposed to fish

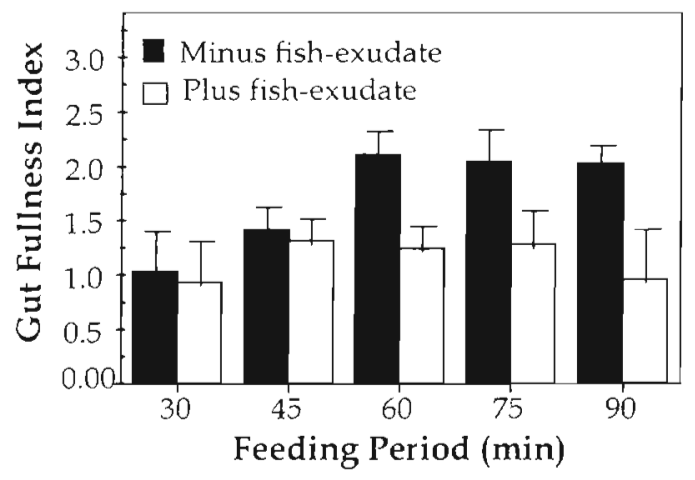

Fig. 2. Acartia tonsa. Gut fullness in the presence and absence of fish exuclates in white light $\left(16 \mu \mathrm{E} \mathrm{m}^{-2} \mathrm{~s}^{-1}\right)$ after different feeding periods. Feeding period; time (min) exposed to food; gut fullness index: ng of total pigment (chlorophyll a + pheopigment a) copepod ${ }^{-1} \mathrm{~mm}^{-1}$ cephalothorax length. Standard error bars are shown

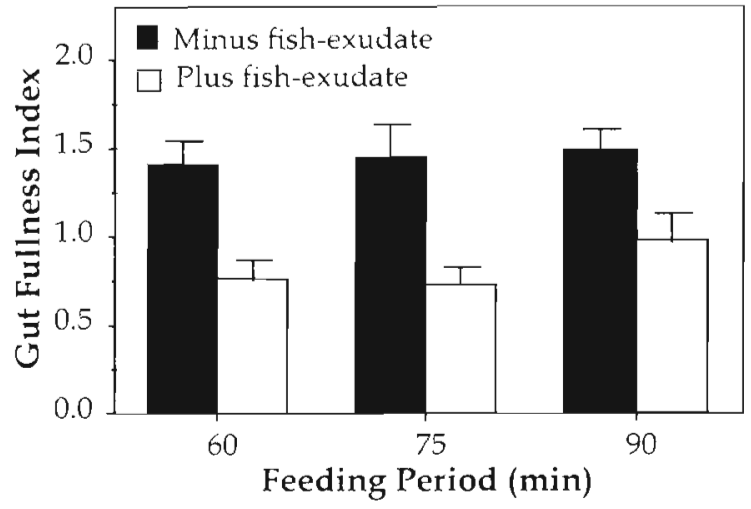

Fig. 3. Acartia hudsonica. Gut fullness in the presence and absence of fish exudates in white light $\left(16 \mu \mathrm{E} \mathrm{m}^{-2} \mathrm{~s}^{-1}\right)$ after different feeding periods. Feeding period: time (min) exposed to food; gut fullness index: ng of total pigment (chlorophyll $a+$ pheopigment a) copepod $\mathrm{d}^{-1} \mathrm{~mm}^{-1}$ cephalothorax length. Standard error bars are shown

exudate compared with FASW controls (Figs. 2 \& 3 ). The duration of the feeding period had no significant effect for either $A$. tonsa (Model I, 2-way ANOVA: $F_{\mathrm{s}}=$ $1.979 ; \mathrm{df}=4,39 ; \mathrm{p}>0.05$ ) or A. hudsonica (Model I, 2way ANOVA: $F_{\mathrm{s}}=0.377 ; \mathrm{df}=2,24 ; \mathrm{p}>0.05$ ). Although A. tonsa shows increases in gut fullness in FASW during the first $60 \mathrm{~min}$, the data set as a whole shows no significant effects of duration of the feeding period for either A. tonsa or A. hudsonica exposed to fish exudate. These 2 species had gut fullness levels 38 and $43 \%$ lower than FASW controls, respectively. Both Stearns (1986) and Bollens \& Stearns (1992) reported similar reductions in the gut fullness of $A$. tonsa individuals in situ during the day compared with nighttime gut fullness levels.

The fish-exudate treatments were prepared in the absence of copepods, and the copepods were not directly exposed to tish during the experiments. Thus, it is unlikely that any chemicals exuded by the copepods in response to direct attack caused a decrease in feeding activity. It is possible that the copepods themselves released a chemical in response to fish exudate, and that this 'copepod chemical' functioned to elicit a reduction in gut fullness in those copepods that perceive it. While this possibility has not been eliminated by this research, it appears unlikely from a strictly Darwinian perspective, since copepods releasing this 'copepod chemical' and perceiving it from others would be the very ones exposed initially to the fish exudate: the exposed zooplankton would be sending chemical messages to already exposed zooplankton. It is more likely that the reduction in gut fullness resulted from the detection by the copepods of a chemical substance produced by the fish. However, it is not known if the fish exudates used in these experiments are sim- 


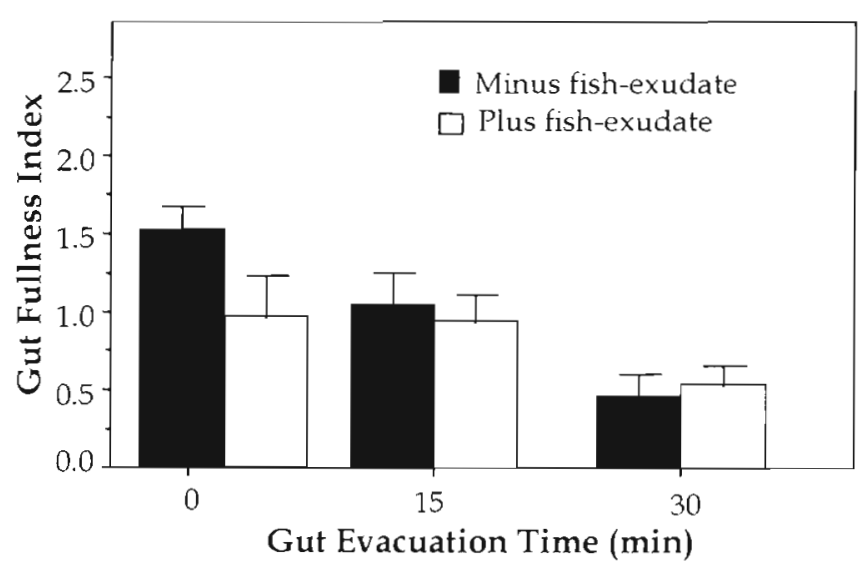

Fig. 4. Acartia tonsa. Gut evacuation in the presence and absence of fish exudates in white light $\left(16 \mu \mathrm{E} \mathrm{m} \mathrm{m}^{-2} \mathrm{~s}^{-1}\right)$. Gut evacuation time: time since removal of food (min); gut fullness index: ng of total pigment (chlorophyll a + pheopigment a) copepod ${ }^{-1} \mathrm{~mm}^{-1}$ cephalothorax length. Standard error bars are shown

ilar to the fish kairomone responsible for induction of nocturnal vertical migration in Daphnia (Loose 1993. Loose et al. 1993).

Gut evacuation rates at $23^{\circ} \mathrm{C}$ were similar regardless of exposure to fish-exuded chemicals, and were similar to rates reported by Stearns et al. (1987) (their Fig. 5). In all cases, most of the gut contents had been evacuated within the first $30 \mathrm{~min}$. Thus gut evacuation activity of Acartia tonsa (Fig. 4) was apparently unaffected by the fish exudate (Model I, 2-way ANOVA: $F_{\mathrm{s}}=$ $1.688 ; \mathrm{df}=1,22 ; \mathrm{p}>0.05)$. Since fish exudate did not induce an increase in gut evacuation rate and since gut fullness is the residual of ingestion minus egestion, any reduction of gut fullness in the copepods in the feeding experiments must have been caused by a reduction in ingestion rate.

Exposure to fish exudate at varying light intensities (Fig. 5) resulted in a highly significant fish/non-fish $x$ light intensity interaction effect (Model I, 2-way ANOVA: $\left.F_{s}=4.377 ; \mathrm{df}=8,72 ; \mathrm{P}<0.01\right)$. Because of this interaction effect, a Model I, 1-way ANOVA was performed to test for significance among the means within each exposure (plus/minus fish exudate) group. No significant differences were found among the groups which had not been exposed to fish exudate (Model I 1 -way ANOVA: $\left.F_{\mathrm{s}}=1.86 ; \mathrm{df}=8,36 ; \mathrm{p}>0.05\right)$. A highly significant difference was found, however, among the groups which were exposed to fish exudates (Model I, 1 -way ANOVA: $F_{\mathrm{s}}=10.08 ; \mathrm{df}=8,36 ; \mathrm{p}<0.01$ ). Further examination using the SNK a posteriori mean separation test (Table 1) revealed significantly lower GFI at light intensities $\geq 1.0 \times 10^{-2} \mu \mathrm{E} \mathrm{m}^{-2} \mathrm{~s}^{-1}(\mathrm{SNK}: \mathrm{n}=90, \mathrm{df}=$ $72, p<0.05$ ) when compared to lower intensities. Thus,

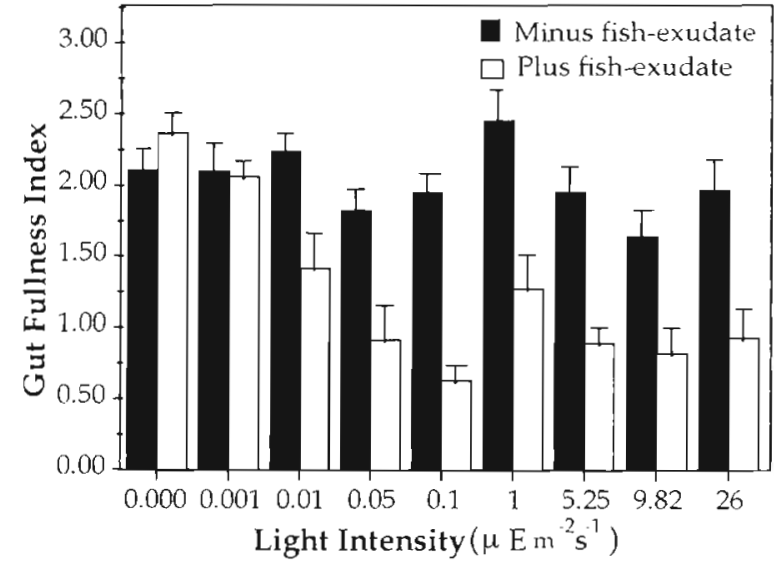

Fig. 5. Acartia tonsa. Gut fullness in the presence and absence of fish exudates at different light intensities. Light intensity: intensity of light striking the surface of the experimental testing chamber in $\mu \mathrm{E} \mathrm{m}^{-2} \mathrm{5}^{-1}$; gut fullness index: ng of total pigment (chlorophyll a + pheopigment a) copepod ${ }^{-1} \mathrm{~mm}^{-1}$ cephalothorax length. Standard error bars are shown

A. tonsa responded to the fish exudate only at light intensities $\geq 1.0 \times 10^{-2} \mu \mathrm{E} \mathrm{m}^{-2} \mathrm{~s}^{-1}$

Research by Nemetz (1996) using the same projector and lamp revealed that for the visual predator Menidia

Table 1. Acartia tonsa. Gut fullness in the presence $(+)$ and absence (-) of fish exudates at different white light intensities Light intensity: intensity of light striking the surface of the water in the experimental chamber in $\mu \mathrm{E} \mathrm{m}^{-2} \mathrm{~s}^{-1} ; \mathrm{n}$ : number of observations; GFI: gut fullness index in ng of total pigment (chlorophyll $a+$ pheopigment a) copepod ${ }^{-1} \mathrm{~mm}^{-1}$ cephalothorax length; SE: standard error of the mean; SNK groups (A and $B$ ): grouping of means after application of Student-Newman-Keuls (SNK) a posteriori mean separation test (SNK: $n=$ $90, \mathrm{df}=72, \mathrm{p}<0.05$ )

\begin{tabular}{|c|c|c|c|c|c|}
\hline $\begin{array}{l}\text { Light } \\
\text { intensity }\end{array}$ & $\begin{array}{c}\text { Fish } \\
\text { exudate }\end{array}$ & $n$ & $\begin{array}{c}\text { Mean } \\
\text { GFI }\end{array}$ & $\mathrm{SE}$ & $\begin{array}{c}\text { SNK group } \\
\text { A } B\end{array}$ \\
\hline 1 & - & 5 & 2.45 & 0.222 & \\
\hline 0 & + & 5 & 2.36 & 0.153 & \\
\hline 0.01 & - & 5 & 2.24 & 0.136 & \\
\hline 0 & - & 5 & 2.11 & 0.151 & \\
\hline 0.001 & - & 5 & 2.09 & 0.208 & \\
\hline 0.001 & + & 5 & 2.06 & 0.106 & \\
\hline 26 & - & 5 & 1.97 & 0.208 & \\
\hline 5.25 & - & 5 & 1.96 & 0.177 & \\
\hline 0.1 & - & 5 & 1.95 & 0.131 & \\
\hline 0.05 & - & 5 & 1.82 & 0.147 & \\
\hline 9.82 & - & 5 & 1.64 & 0.185 & \\
\hline 0.01 & + & 5 & 1.42 & 0.250 & 1 \\
\hline 1 & + & 5 & 1.27 & 0.239 & \\
\hline 26 & + & 5 & 0.92 & 0.211 & \\
\hline 0.05 & + & 5 & 0.91 & 0.245 & \\
\hline 5.25 & + & 5 & 0.90 & 0.102 & \\
\hline 9.82 & + & 5 & 0.83 & 0.174 & \\
\hline 0.1 & + & 5 & 0.63 & 0.106 & \\
\hline
\end{tabular}


menidia (after dark adaptation) the lowest white light intensity needed to elicit an appreciable phototactic response occurs near $10^{-5} \mu \mathrm{E} \mathrm{m}^{-2} \mathrm{~s}^{-1}$. Blaxter (1968a, b, 1969) concluded that the minimal light intensity needed for visual predation by planktivorous fish is 3 to 4 orders of magnitude greater than the minimal intensity that can elicit a phototactic response. Thus, using Blaxter's approach and Nemetz's (1996) intensity, the minimal light intensity needed for visual pre-

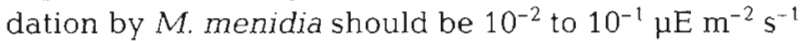
Copepods exposed to fish exudates below this estimated visual predation threshold had significantly higher GFIs (Table 1).

Minimal light intensities needed to elicit phototactic responses for Clupea harengus, Pleuronectes platessa, and Solea solea are apparently lower than those stimulating Menidia menidia (Blaxter 1968a, b, 1969). Stearns et al. (1994) estimated the minimal light intensity needed by Sciaenops ocellatus larvae for visual predation to be between $10^{-4}$ and $10^{-3} \mu \mathrm{E} \mathrm{m}^{-2} \mathrm{~s}^{-1}$, using Blaxter's (1968a,b, 1969) approach, and Nemetz (1996) noted that there was some evidence for a phototactic response at lower $\left(9.5 \times 10^{-8} \mu \mathrm{E} \mathrm{m}^{-2} \mathrm{~s}^{-1}\right)$ light intensities for $M$. menidia. This would lower $M$. menidia's visual

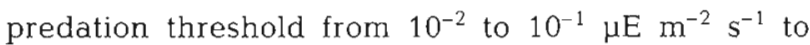
between $10^{-4}$ and $10^{-3} \mu \mathrm{E} \mathrm{m}^{-2} \mathrm{~s}^{-1}$. Thus, there may be a difference between the minimal light intensity needed for visual predation and the threshold light intensity for the chemically induced response of the copepods.

On 2 occasions, Stearns \& Forward (1984) measured the light intensity in the Newport River estuary, North Carolina, USA, every $5 \mathrm{~min}$ during sunset until light intensity reached $10^{-4} \mu \mathrm{E} \mathrm{m} \mathrm{m}^{-2} \mathrm{~s}^{-1}$ (their Fig. 5B, C). They reported that light intensities dropped from $10^{-2}$ to $10^{-4} \mu \mathrm{E} \mathrm{m} \mathrm{m}^{-2} \mathrm{~s}^{-1}$ in approximately 15 to $30 \mathrm{~min}$. Thus, there appears to be a narrow temporal window during twilight when light levels are high enough for visual predation $\left(\geq 10^{-4} \mu \mathrm{E} \mathrm{m}^{-2} \mathrm{~s}^{-1}\right)$ but not high enough to trigger the chemically mediated response of Acartia tonsa. During this 15 to $30 \mathrm{~min}$ low-light period it is possible that the risk of visual predation is low compared with the potential nutritional gain by feeding. It should be noted, however, that direct measurements of Menidia menidia's visual predation threshold are unavailable. As such, interpretations of the aforementioned difference are speculative.

Nocturnal vertical migration and nocturnal feeding are similar behavioral responses that reduce the risk of visual predation. Both are advantageous in the presence of visual predators, and disadvantageous in their absence. Both are known to be induced by fish-mediated cues. The induction of nocturnal vertical migration requires both daytime light levels and a fish-mediated mechanical cue for Acartia hudsonica (Bollens \&
Frost 1991). The current study indicates that daytime reduction of feeding requires both daytime light levels and a fish-mediated chemical cue. These findings support the view that nocturnal vertical migration and nocturnal feeding are separate, independent behaviors (Head et al. 1985, Stearns 1986) since they are apparently elicited by different cues. It must be noted, however, that mechanical cues were not tested during this research and may affect copepod grazing behavior in addition to chemical cues. As such, the possibility of mechanical cues affecting copepod grazing behavior cannot be discounted.

In the current study, only chlorophyll-containing food items were provided. Because grazing on chlorophyll-containing food items (e.g. phytoplankton) increases visibility, a change to feeding on non-chlorophyll containing food items (e.g. microzooplankton) might provide an advantage when visual predators are abundant. There is evidence that visual predation pressure on copepods that host chlorophyll-containing epibionts is higher than on copepods that host nonphotosynthetic epibionts (Willey et al. 1993). Additional research is needed to determine if, in situ, overall feeding is reduced in the daytime presence of visual predators or if in fact there is a change to less visible food items.

This research, combined with that of Bollens \& Stearns (1992), indicates a hierarchy of environmental cues regulating feeding activity of both Acartia tonsa and Acartia hudsonica. Under light conditions where visual predation is possible, feeding is reduced when exudates of the visual predator are present. Appropriate light and chemical cues must both be present to elicit this response. Other environmental cues (e.g. temperature, nutritional status) may affect copepod feeding behavior. How these factors might interact to influence feeding dynamics in natural plankton systems is at present largely unknown.

Acknowledgements. We thank the following people for their advice and support during this research: Dr Mark Morgan, Dr John Dighton, and Dr William Bacha. We thank the following people for their technical assistance: V Shaffer (Virginia Institute of Marine Science), S. Kilham (Drexel University), J. Nemetz, A. Carrado, C. Langman (Rutgers University, Camden). We also thank 4 anonymous reviewers for their constructive comments. The first author thanks J. D. Cieri, D. Cieri-Tanis, and D. Cieri for their support. This research was sponsored in part by Rutgers University Institute of Marine and Coastal Sciences Grant Nos. 2-01165 and 2-01160 to D.E.S. and M. Morgan, respectively, and the Department of Biology, Rutgers University, Camden. This is Contribution No. 98-23 of the Rutgers University Institute of Marine and Coastal Sciences. M.C. would like to dedicate this article to J.D.C., in loving memory. 


\section{LITERATURE CITED}

Arashkevich YG (1975) Duration of digestion in marine copepods. Tr Inst Okeanol im P P Shirshova 102:351-357 (Transl Ser Fish Mar Serv Can 3598:1-13)

Arfi R, Leveau M, Pagano M (1992) Diel variations of the filtering rate by the copepod Acartia tonsa on the natural phytoplankton in Berre lagoon. CR Acad Sci III-Vie 314: 213-218

Blaxter JHS (1968a) Visual thresholds and spectral sensitivity of herring larvae. J Exp Biol 48:39-53

Blaxter JHS (1968b) Light intensity, vision, and feeding in young plaice. J Exp Mar Biol Ecol 2:293-307

Blaxter JHS (1969) Visual thresholds and spectral sensitivity of flatfish larvae. J Exp Biol 51:221-230

Bollens SM, Frost BW (1991) Diel vertical migration in zooplankton: rapid individual response to predators. J Plankton Res 13:1359-1366

Bollens SM, Stearns DE (1992) Predator-induced changes in the diel feeding cycle of a planktonic copepod. J Exp Mar Biol Ecol 156:179-186

Cieri MD (1996) Reduction in grazing activity by two estuarine copepods in response to the chemical presence of a visual predator. Masters thesis, Department of Biology, Rutgers, The State University of New Jersey, Camden

Dodson S (1988) The ecological role of chemical stimuli for the zooplankton: predator-avoidance behavior in Daphnia. Limnol Oceanogr 33:1431-1436

Giguère LA, Northcote TG (1987) Ingested prey increase risks of visual predation in transparent Chaoborus larvae. Oecologia 73:48-52

Haney JF (1988) Diel patterns of zooplankton behavior. Bull Mar Sci 43:583-603

Head EJ, Harris LR, Debs AC (1985) Effects of day length and food concentration on in situ diurnal feeding rhythms in Arctic copepods. Mar Ecol Prog Ser 24:281-288

Kislalioglu K, Gibson RN (1976) Some factors governing prey selection by the 15-spined stickleback, Spinachia spinachia (L.). J Exp Mar Biol Ecol 25:159-169

Loose CJ (1993) Daphnia diel vertical migration behavior: response to vertebrate predator abundance. Arch Hydrobiol Beih Ergebn Limnol 39:29-36

Loose CJ, von Elert E, Dawidowicz P (1993) Chemicallyinduced diel vertical migration in Daphnia: a new bioassay for kairomones exuded by fish. Arch Hydrobiol 126: 329-337

McAllister CD (1971) Some aspects of nocturnal and continuous grazing by planktonic herbivores in relation to production studies. Fisheries Research Board of Canada Technical Report No. 247. Fisheries Research Board of Canada, Biological Station, Namaimo, BC

Editorial responsibility: Otto Kinne (Editor), Oldendorf/Luhe, Germany
Nemetz JD (1996) Photosensitivity of an estuarine visual planktivore, the Atlantic silverside Menidia menidia. Masters thesis, Department of Biology, Rutgers, The State University of New Jersey, Camden

O'Brien WJ (1979) The predator-prey interactions of planktivorous fish and zooplankton. Am Sci 67:572-581

Ringelberg $\mathrm{J}$ (1991) A mechanism of predator-mediated induction of diel vertical migration in Daphnia hyalina. J Plankton Res 13:83-89

Sokal R, Rohlf FJ (1969) Biometry. WH Freeman \& Co, New York

Sokal R, Rohlf FJ (1987) Introduction to biostatistics, 2nd edn WH Freeman and $\mathrm{Co}$, New York.

Stearns DE (1983) Control of nocturnal vertical migration in the calanoid copepod Acartia tonsa Dana in the Newport River estuary, North Carolina. PhD dissertationDepartment of Zoology, Duke University, Durham, NC

Stearns DE (1986) Copepod grazing behavior in simulated natural light and its relation to nocturnal feeding. Mar Ecol Prog Ser 30:65-76

Stearns DE, Forward RB (1984) Copepod photobehavior in a simulated natural light environment and its relation to nocturnal vertical migration. Mar Biol 82:91-100

Stearns DE, Litaker W, Rosenberg G (1987) Impacts of zooplankton grazing and excretion on short-interval fluctuations in chlorophyll $a$ and nitrogen concentrations in a well-mixed estuary. Estuar Coast Shelf Sci 24:305-325

Stearns DE, Tester PA, Walker RL (1989) Diel changes in the egg production rate of Acartia tonsa (Copepoda, Calanoida) and related environmental factors in two estuaries. Mar Ecol Prog Ser 52:7-16

Stearns DE, Holt GJ, Forward RB, Pickering PL (1994) Ontongeny of phototactic behavior in red drum larvae (Sciaenidae: Sciaenops ocellatus). Mar Ecol Prog Ser 104: $1-11$

Strickland JDH, Parsons TR (1972) A practical handbook of seawater analysis, 2nd edn. Bull Fish Res Bd Can 167 $1-311$

Timofeeva VA (1974) Optics of turbid waters (results of laboratory studies). In: Jerlov NG, Steeman E, Nielsen N (eds) Optical aspects of oceanography. Academic Press, New York, p 177-219

Willey RL, Willey RB, Threlkeld ST (1993) Planktivore effects on zooplankton epibiont communities: epibiont pigmentation effects. Limnol Oceanogr 38:1818-1828

Yentsch C, Menzel D (1963) A method for the determination of phytoplankton chlorophyll and phaeophytin by fluorescence. Deep-Sea Res 10:221-231

Zaret TM (1972) Predators, invisible prey, and the nature of polymorphism in the Cladocera (Class Crustacea). Limnol Oceanogr 17:171-184

Submitted: November 21, 1996; Accepted: September 28, 1998 Proofs received from author(s): January 21, 1999 